\title{
The Primary Healthcare Nurse Practitioner Role in Canada
}

Faith Donald, NP-PHC, PhD (co-lead author) Associate Professor, Daphne Cockwell School of Nursing, Ryerson University Affiliate Faculty, CHSRF/CIHR Chair Program in Advanced Practice Nursing (APN) Toronto, ON

Ruth Martin-Misener, NP, PhD (co-lead author) Associate Professor \& Associate Director, Graduate Programs, School of Nursing, Dalhousie University Affiliate Faculty, CHSRF/CIHR Chair Program in APN Halifax, NS

Denise Bryant-Lukosius, RN, PhD Assistant Professor, School of Nursing \& Department of Oncology, McMaster University Senior Scientist, CHSRF/CIHR Chair Program in APN

Director, Canadian Centre of Excellence in Oncology Advanced Practice Nursing (OAPN) at the Juravinski Cancer Centre at Hamilton Health Sciences

Hamilton, ON

Kelley Kilpatrick, RN, PhD

Postdoctoral Fellow, CHSRF/CIHR Chair Program in APN

Professor, Department of Nursing, Université du Québec en Outaouais

St-Jérôme, QC

Sharon Kaasalainen, RN, PhD

Associate Professor, School of Nursing, McMaster University

Career Scientist, Ontario Ministry of Health and Long-Term Care

Affiliate Faculty, CHSRF/CIHR Chair Program in APN

Hamilton, ON

Nancy Carter, RN, PhD

CHSRF Postdoctoral Fellow

Junior Faculty, CHSRF/CIHR Chair Program in APN

McMaster University

Hamilton, ON

Patricia Harbman, NP-PHC, MN/ACNP Certificate, PhD(c), University of Toronto Graduate student in CHSRF/CIHR Chair Program in APN

Oakville, ON

Ivy Bourgeault, PhD

ClHR/Health Canada Research Chair in Health Human Resource Policy

Scientific Director, Population Health Improvement Research Network and Ontario Health 
Human Resources Research Network

Professor, Interdisciplinary School of Health Sciences, University of Ottawa

Ottawa, ON

Alba DiCenso, RN, PhD

CHSRF/CIHR Chair in APN

Director, Ontario Training Centre in Health Services \& Policy Research

Professor, Nursing and Clinical Epidemiology \& Biostatistics, McMaster University Hamilton, ON

\begin{abstract}
Primary healthcare nurse practitioners (PHCNPs), also known as family or all-ages nurse practitioners, are the fastest growing advanced practice nursing role in Canada. All 10 provinces and three territories now have legislation that authorizes their role. Their introduction is linked to countrywide health reform efforts to improve the accessibility and quality of primary healthcare.
\end{abstract}

This paper focuses on the PHCNP role and draws on the results of a scoping review of the literature and qualitative key informant interviews conducted for a decision support synthesis commissioned by the Canadian Health Services Research Foundation and the Office of Nursing Policy in Health Canada. The overall objective of this synthesis was to develop a better understanding of advanced practice nursing roles and the factors that influence their effective development and integration in the Canadian healthcare system.

Based on synthesis findings, we describe the current status of PHCNP roles in Canada and describe three important challenges to their integration and long-term viability: restrictive legislation and regulation, inconsistencies in educational preparation across Canada and working relationships between PHCNPs and family physicians. We conclude that although there has been considerable progress made in integrating PHCNPs into the Canadian healthcare system and there is mounting evidence to support the value of the role, there is more to do to fully integrate and sustain the role. A pan-Canadian approach is needed to the education, supply, legislation and regulation of PHCNPS, as well as further dialogue at all levels to enhance how PHCNPS and family physicians can work together to provide optimal primary healthcare.

\title{
Introduction
}

The predecessors of today's primary healthcare nurse practitioners (PHCNPs) began their practice in the Canadian North more than 100 years ago. These early PHCNPs, known most commonly as outpost nurses, were introduced by religious organizations to improve primary healthcare services for underserviced populations (Graydon and Hendry 1977; Kaasalainen et al. 2010; Kulig et al. 2003). 
It was not until the early 1970s, when the Canadian healthcare system was experiencing a shortage of family physicians, that the first wave of PHCNPs was introduced in southern urban communities. National and provincial attention was directed toward defining their role and scope of practice, determining education standards and evaluating the effectiveness of the role (Kaasalainen et al. 2010). PHCNPs provided expanded primary healthcare services to individuals and families, mostly in family practice offices or community health centres (Kergin et al. 1973). Collaboration with family physicians and other healthcare team members was an expectation of the PHCNP role and was integral to PHCNP role descriptions. Despite the positive results of several randomized controlled trials evaluating the effectiveness of PHCNP care (Chambers and West 1978; Spitzer et al. 1973, 1974), implementation efforts ground to a halt in the mid-1980s for a variety of reasons. These included a lack of remuneration mechanisms for PHCNPs, reduced physician income, lack of nurse practitioner (NP) role legislation for an extended scope of practice, inadequate support from policy makers and other health providers, and a perceived oversupply of physicians, particularly in urban areas (Kaasalainen et al. 2010; Spitzer 1984). Consequently, PHCNPs disappeared in all but remote areas and a few sites in southern Canada.

In the mid-1990s to the early 2000s, numerous federal and provincial government reports, all calling for major primary healthcare reform, identified that the use of nurses and other healthcare professionals could improve patient access to health services (Kirby 2002; Mhatre and Deber 1992; Romanow 2002; Stoddart and Barer 1992). Reform efforts were fuelled by unprecedented federal and provincial investments in primary healthcare infrastructure and interdisciplinary healthcare teams, leading to a countrywide emphasis on enhancing health promotion and improving equitable healthcare access and quality (Hutchison 2008). This context prompted the revival of governments' interest in the PHCNP role and initiated the second wave of PHCNP role implementation, supported by legislation, regulation, remuneration mechanisms and funded education programs. Foundational to implementing this role is the abundant research that has shown PHCNPs are effective, safe practitioners who positively influence patient, provider and health system outcomes (Dierick-van Daele et al. 2010; Horrocks et al. 2002).

In this paper we examine the current status of the PHCNP role in Canada, including supply, deployment and practice settings; education; and regulation and scope of practice. We summarize key issues and challenges to the integration and long-term viability of the PHCNP role and offer recommendations to address the challenges. While PHCNPs are also known as family or all-ages NPs, we will use "PHCNPs" for the purposes of this paper. 


\section{Methods}

This paper was developed using the results of the scoping review of the literature and key informant interviews conducted for a decision support synthesis commissioned by the Canadian Health Services Research Foundation (CHSRF) and the Office of Nursing Policy in Health Canada (DiCenso et al. 2010b). The literature review and interviews were carried out to develop a better understanding of advanced practice nursing roles (NP and clinical nurse specialist [CNS]), their current use, and the individual, organizational and health system factors that influence their effective development and integration in the Canadian healthcare system.

The synthesis methods are described in detail in an earlier paper in this issue (DiCenso et al. 2010c). Briefly, we conducted a comprehensive appraisal of published and grey literature ever written about Canadian advanced practice nursing roles as well as reviews of the international literature from 2003 to 2008. The overall search yielded a total 2,397 papers, of which 468 were included in the scoping review. Data were extracted from each paper and themes were developed. The PHCNP-related papers contributed $47 \%$ of the Canadian papers included in the synthesis. A total of 69 papers were primary studies, 19 were reviews and the remaining articles were essays or editorials.

Interviews ( $n=62)$ and focus groups ( $n=4$ with a total of 19 participants) were conducted in English or French with national and international key informants including NPs, CNSs, physicians, healthcare team members, educators, healthcare administrators, nursing regulators and government policy makers. We used purposeful sampling to identify participants with a wide range of perspectives on advanced practice nursing issues in Canada and internationally. All key informants were asked the same questions, some of which related to the PHCNP role. The interview questions are described in detail elsewhere (DiCenso et al. 2010c); briefly, they focused on reasons for introducing the advanced practice nursing role(s) in interviewees' organizations, regions or provinces; how the role(s) were implemented; key factors facilitating and hampering their full integration at the individual, organizational and system-level; the nature of their collaborative relationships; their impact; success stories; and interviewees' recommendations for fully integrating the role. Nearly all of the key informants discussed the PHCNP role. We developed an initial coding structure of emergent themes from the interviews and integrated this structure into a broader, theoretically informed framework that included factors influencing advanced practice nursing role integration (Bryant-Lukosius and DiCenso 2004; Bryant-Lukosius et al. 2004). When our synthesis was completed, CHSRF convened a multidisciplinary roundtable to develop recommendations for policy, practice and research. 
We synthesized the literature and interview/focus group data by examining the similarities and differences in themes and common patterns and trends. For this paper, we focus on findings specific to the PHCNP role in Canada and refer to the roundtable recommendations where relevant.

\section{Results}

We begin our presentation of the findings with a review of the current status of the PHCNP role in Canada, describing supply, deployment and practice settings; education; regulation and scope of practice; and liability. Subsequently, we describe the issues and challenges that most frequently and consistently emerged from our various data sources: restrictive legislation and regulation, inconsistencies in educational preparation, and the working relationships between PHCNPs and family physicians.

\section{Current Status of the PHCNP Role in Canada}

The potential of PHCNPs to enhance the accessibility and quality of primary healthcare services has sparked nationwide interest. Perhaps because of this, the PHCNP role is the fastest-growing advanced practice nursing role in Canada (Canadian Institute for Health Information [CIHI] 2010). This growth has been supported by professional, regulatory and government nursing leaders (Carter et al. 2010) and by the establishment of provincial/territorial NP associations, some of which are connected with the Canadian Association of Advanced Practice Nurses (CAAPN).

During the latter part of the 1990s and throughout the 2000s, provinces and territories each developed their own legislation and regulation for the PHCNP role (CIHI 2010). Although there was some inter-jurisdictional consultation, the timing and pace of development depended on factors internal to each province and territory. The result was a mélange of legislation and regulation. Titles, title protection and scope of practice were common points of difference. Realizing that an integrated approach was needed for sustainability of the role within the country, nursing leaders proposed development of a pan-Canadian framework. Subsequently, the Canadian Nurse Practitioner Initiative (CNPI) was funded by Health Canada and sponsored by the Canadian Nurses Association (CNA) (CNA 2008). Under the leadership of the CNPI, extensive literature reviews and discussion papers were prepared on practice, education, legislation, human resource planning and social marketing, all in relation to the NP role in the Canadian healthcare system. Specific accomplishments included development and revision of the Canadian Nurse Practitioner Core Competency Framework (CNA 2005, 2010), a framework that identified the competencies common to all NPs irrespective of specialization; the Canadian Nurse Practitioner Examination (CNPE) (CNPI 2006b), developed for PHCNPs only; the Implementation and Evaluation 
Toolkit for Nurse Practitioners in Canada (CNPI 2006a); and frameworks for practice, education, legislation and regulation (CNPI 2006c).

The purpose of the CNPI's legislative and regulatory framework (2006c) was to protect public interests, facilitate healthcare access, ensure nationwide consistency, support workforce mobility and position NPs to enable their maximum contribution to the Canadian healthcare system. The following generic definition of NPs was developed and recommended for use in Canada:

Nurse practitioners are registered nurses with additional educational preparation and experience who possess and demonstrate the competencies to autonomously diagnose, order and interpret diagnostic tests, prescribe pharmaceuticals and perform specific procedures within their legislated scope of practice (CNA 2008: 16, 2009).

Although there is no national definition for a PHCNP, it is generally accepted that PHCNPs provide services to individuals and families across the lifespan and work in a variety of community-based settings (DiCenso et al. 2003, 2007). The focus of their practice is health promotion, preventive care, diagnosis and treatment of acute common illnesses and injuries, and monitoring and management of stable chronic conditions (Caty et al. 2000; DiCenso et al. 2003; Goss Gilroy Inc. Management Consultants 2001; Sidani et al. 2000; Way et al. 2001). Using an evidence-informed holistic approach that emphasizes health promotion and partnership development, NPs complement rather than replace other healthcare providers. Interview participants concurred, explaining that PHCNPs were introduced to improve accessibility to a range of primary healthcare services and enhance the quality of chronic disease management. A government interview participant summarized this perspective as follows:

I think that in the guidelines produced by the [provincial] Nurses' Association, it [PHCNP role] is very well defined; it's the intake of vulnerable clients that say they are dealing with a chronic disease. I think that forms an integral part because as time goes on ... this clientele is going to increase, so we think about diabetes, heart failure, chronic obstructive lung disease, kidney failure, heart failure ... all the chronic diseases that worsen and will increase in number.... Monitoring pregnancies, also the intake of routine health problems, that is essential, and the monitoring they [PHCNPs] can conduct with people from birth to adulthood, people who are ambulatory, in terms of [disease] prevention, [health] promotion, to ensure that they help people adopt suitable healthy behaviours to care for themselves. I would say that it [PHCNP role] centres primarily around these roles. 


\section{Supply, Deployment and Practice settings}

Since 2005, CIHI has reported the numbers of NPs in Canada along with demographic data. These reports are based on annual registration data from provincial and territorial nursing regulatory bodies. The most recent statistics, reflecting 2008 registration data, indicate that the number of licensed NPs in Canada more than doubled between 2004 and 2008, increasing from 800 to 1,626 (CIHI 2010). In $2008,95 \%$ of NPs were female; approximately $76 \%$ worked in urban areas while $24 \%$ worked in rural and remote areas; and over $50 \%$ of NPs were located in Ontario. The majority of NPs worked full-time (76\%), and 94\% reported their main responsibility was direct patient care. Although these data do not distinguish between types of NPs, in 2008 it is reasonable to assume that the majority of licensed NPs in Canada were PHCNPs. This is because in Ontario, where the largest number of NPs are registered, acute care NPs (ACNPs) did not begin writing registration examinations until 2008 (Nurse Practitioners' Association of Ontario 2009), and therefore very few would be counted as licensed in the 2008 regulatory data provided to CIHI. In addition, some provinces, for example, New Brunswick, license only the PHCNP role.

In 2008, approximately $40 \%$ of PHCNPs worked in the community sector, $32 \%$ in the hospital sector and $2.4 \%$ in the nursing home or long-term care sector; the remainder worked in "other" places or did not state their place of employment (CIHI 2010). Another survey of 371 Ontario PHCNPs in 2004-2005 found that the majority of respondents reported working with marginalized populations (low-income earners, unemployed persons, substance abusers, people with mental illness, cultural minorities, recent immigrants and HIV/AIDS patients), and over half (57\%) worked in underserviced locations (van Soeren et al. 2009). There is evidence that PHCNP deployment is expanding to settings that have not previously employed PHCNPs, such as emergency departments, long-term care settings and cancer care centres (DiCenso et al. 2007; Donald et al. 2009; Ordre des infirmières et infirmiers du Québec 2009; Stolee et al. 2006).

Practice and expectations for the role, as well as the longevity of the role in the setting and amount of experience in the role, influence PHCNP practice patterns (Caty et al. 2000; DiCenso et al. 2003; Goss Gilroy Inc. Management Consultants 2001; Sidani et al. 2000; Way et al. 2001). DiCenso et al. (2003) identified three major focuses for PHCNP practice: condition based, population based or scope based. In each of these practice models, the PHCNP worked autonomously and consulted or collaborated with the physician as needed. With a condition-based focus, the PHCNP practice was primarily based on a specific patient condition (e.g., congestive heart failure, diabetes, mental health issues or for chronic disease management). With a population-based focus, the PHCNP practice was primarily based on a specific type of patient population or geographic area (e.g., teenagers, 
children, marginalized people or First Nations people). With a scope-based focus, the PHCNP primarily saw a broad-based primary care patient population and consulted or collaborated with the physician mainly with respect to issues beyond the PHCNP's scope.

Data from interview participants concurred with the literature. The following quotes from PHCNP interview participants show how their day-to-day practice activities vary in different settings:

So I see patients from birth to death, for a variety of problems - complex to simple problems. So there's nothing that I really am not able to see, and generally if there's something that's out of my scope, I'll do what any family doctor would do, either consult or refer to a specialist.

I go to the school every Monday morning, and I'm a resource person and have some teen clients that find it easier to come and see me there.... I probably spend half to three-quarters of a day and probably eight hours a week seeing diabetic clients, and I do a monthly presentation at the library.... The bulk of my time is direct patient care, but I have implemented a number of different educational programs and outreach, and I collaborate with mental health and public health and the different nurses and practitioners in other areas with some of the projects they have.

So in some ways our role [in northern remote communities] is broader than that of a family NP in that we see anybody who comes in through the door. So we provide public health services, maternal-child, well-women, prenatal care and, in addition, we see what would normally be seen in a walk-in clinic, so acute, episodic illness. We also provide emergency care, which can extend from minor emergencies to life-threatening emergencies. We work Monday to Friday in the clinic, and then we provide on-call services after hours. This is the model across northern Canada and in most First Nations and Inuit communities.

The estimated average length of time Canadian PHCNPs spend per patient visit is 30 minutes (CNPI 2006c). This is consistent with an Ontario study that found PHCNPs in primary care settings provided services for an average of 14 patients per day; in long-term and acute care the daily number was 26 (van Soeren et al. 2009).

\section{Education}

Since the 1970s, there has been countrywide consensus that additional specific education beyond a baccalaureate or diploma program is needed to prepare for PHCNP role requirements. During the second wave of NP implementation, 
PHCNP education programs were initiated in most provinces and territories, beginning in the mid-1990s with the Council of Ontario University Programs in Nursing (COUPN) post-baccalaureate PHCNP Certificate Program (Cragg et al. 2003; Kaasalainen et al. 2010). Other provinces and territories followed suit, with some developing programs at the post-diploma or post-baccalaureate level and others at the master's level (CNPI 2006c). As of 2008, a master's degree from an approved graduate level PHCNP program became the recommended educational standard in Canada and internationally (CNA 2008; International Council of Nurses 2008). That said, only about a third (36.7\%) of Canadian NPs meet this standard (CIHI 2010), and two provinces continue to offer PHCNP education at the baccalaureate or post-baccalaureate level (Newfoundland and Labrador, and Saskatchewan). While Ontario prepared PHCNPs at the post-baccalaureate level for 12 years, the PHCNP education program now provides graduate levels courses at all nine universities that offer the program. The inconsistency in the education of PHCNPs is a key issue challenging PHCNP role integration and is discussed later in this paper and in another paper in this special issue (Martin-Misener et al. 2010).

\section{Regulation and Scope of Practice}

All 10 provinces and three territories in Canada now have legislation authorizing PHCNPs to implement their advanced nursing role (CIHI 2010; Government of Yukon 2009). Many, but not all, provinces and territories protect the title "nurse practitioner" and licensing nomenclature (e.g., RN-NP), and processes vary. Although most jurisdictions require entry-level PHCNPs to complete an examination to qualify for licensure and/or registration, they differ with respect to the nature of the examination; some use the national CNPE, which is written, while others use examinations approved by their province. For example, the Quebec PHCNP certification exam consists of three parts: a written short answer exam, a structured oral interview and an objective structured clinical exam (Personal Communication with Judith Leprohon, Scientific Director, Ordre des infirmières et infirmiers du Québec, March 22, 2010), whereas British Columbia uses the American Nurses Credentialing Center exam (not marked on questions relating to the American healthcare system) and an objective structured clinical exam (College of Registered Nurses of British Columbia 2009).

In most jurisdictions, PHCNPs are authorized to make and communicate a diagnosis of disease, order and interpret diagnostic and screening tests, and prescribe medication (CIHI and CNA 2006). However, some jurisdictions apply restrictions on which diseases NPs may diagnose (Prendergast 2009), and in Quebec, establishing a primary diagnosis remains the exclusive domain of physicians (Gouvernement du Québec 2005). 
Other inter-jurisdictional variations in the scope of PHCNP practice include differences in prescribing privileges and the ability to refer to a specialist. Some provinces have prescribing legislation and regulation that restrict PHCNPs to prescribing from a specified list of drugs (Marchildon 2005), whereas other provinces use an approach based on individual knowledge, education and competence. Schreiber et al. (2005: 9) describe such a professional practice model as one "in which each provider has sole authority for his or her own practice, responsibility for decision-making and maintenance of competencies, and assessment of limitations and areas for professional development." Recently some jurisdictions, for example Nova Scotia and Newfoundland and Labrador, have changed to a broader approach because the list method is cumbersome and cannot keep pace with changes in evidence-informed practice. In December 2009, Ontario passed Bill 179 , which will do away with the use of lists for prescribing and ordering diagnostic and laboratory tests (Ministry of Health and Long-Term Care 2009).

\section{Liability}

PHCNPs are expected to carry adequate liability coverage. Many receive this through the Canadian Nurses Protective Society (CNPS) provided through CNA membership; the CNPS provides $\$ 5$ million of occurrence-based coverage for NPs (http://www.cnps.ca). The autonomous nature of PHCNP practice has created physician concerns related to liability, as physicians have expressed confusion regarding their medico-legal responsibility when in practice with an NP, the adequacy of NP liability insurance coverage and vicarious liability (for example, DiCenso et al. 2003; Jones and Way 2004; Martin-Misener et al. 2004; Turris et al. 2005). Two joint policy statements by the CNA, the Canadian Medical Association and the Canadian Pharmacists Association (CNA 2003) and by the Canadian Medical Protective Association (CMPA) and the CNPS (2005) provided principles and criteria for defining scopes of practice and clarified liability issues. A government interview participant commented that the joint statement from the CMPA and CNPS has alleviated concerns around liability. However, issues remain, since not all PHCNPs are required to choose CNPS coverage and other malpractice insurance plans may not be as comprehensive. Bill 179 in Ontario requires all regulated healthcare providers to carry liability coverage (Ministry of Health and Long-Term Care 2009).

Key Issues and Challenges to PHCNP Role Integration Synthesis of the literature and the participant interview and focus group data revealed that the most frequently and consistently identified challenges limiting the full integration of the PHCNP role into the Canadian healthcare system are (1) restrictive legislation and regulation, (2) inconsistencies in the educational preparation of PHCNPs across Canada and (3) working relationships between PHCNPs and family physicians. 


\section{Restrictive Legislation and Regulation}

Although there have been some successes, legislation and regulation issues continue to create barriers to PHCNP practice, restricting role integration and compromising efficiencies. Many papers in our scoping review reported legislative and regulatory restrictions on PHCNP scope of practice (e.g., Advisory Committee on Health Human Resources et al. 2001; de Witt and Ploeg 2005; DiCenso et al. 2007; Fahey-Walsh 2004; Goss Gilroy Inc. Management Consultants 2001; Gould et al. 2007; Humbert et al. 2007; Nova Scotia Department of Health 2004; Nurse Practitioners' Association of Ontario 2007). One of these barriers is legislation that restricts PHCNP prescribing. At the provincial/territorial level the issue is the use of drug lists and formularies, while at the federal level it is the prescribing of narcotics and controlled substances.

Interview participants in our synthesis repeatedly indicated the "list approach" to prescribing was problematic. Lists became rapidly out of date, were restrictive to practice and added costs and inefficiencies to health service delivery because NPs had to wait for a physician to sign a prescription or to order a test. The following quotes from two interview participants - an administrator and a regulator reflect this dissatisfaction:

[Lists are] a real barrier to practice. So you hire an NP and the NP needs to work around if there are certain drugs that come on the market - it would actually be better for her to prescribe but she can't prescribe them. She's got to go to a physician to prescribe this particular drug. So those are the kinds of things that add to the barriers from a systems perspective, and they add to the inability to hire. I think it adds to the barriers that nurse practitioners come up against. There's a lack of knowledge of what their [NP] full scope of practice can and should be.

We just have to get rid of lists because we have lists of medications and we have lists of tests that an [NP] can order. Of course, healthcare changes all the time. I think rather than having all those lists that are very constraining and out of date pretty much the day that they're passed, we really need to move beyond that into more broad categories and allowing nurses to use their own knowledge, skill and judgment to decide when and what they can order within those categories, which might be constrained but I think the legislation as it stands right now doesn't work. I actually think that there's starting to be some realization at the level of the government that it doesn't work.

Another example of a jurisdictional difference in scope of practice resulting from legislative and regulatory policy was the ability of PHCNPs to refer to medical 
specialists. In some jurisdictions, higher rates of remuneration are paid to medical specialists for patient referrals made by a physician, thereby preventing PHCNPs from making referrals to specialists (DiCenso et al. 2003; Gould et al. 2007). Interview participants commented further that other legislative barriers restricted NP practice and interrupted continuity of patient care. The following quotes from healthcare administrator participants in two provinces illustrate this:

One of the other biggest barriers is the Public Hospitals Act in Ontario. So for example, the Public Hospitals Act doesn't allow an NP to admit or discharge. They [NPs] can care for the person [using medical directives] while they're in the hospital, but they can't admit them and they can't discharge them. And if they truly are a PHCNP, and particularly in the rural and remote areas, you have to have a physician to admit a person but that physician doesn't know that person at all. The NP knows the person. And the argument the physician would make on that is that that's not primary healthcare then. But it's about being client centered. And I think that's the piece ... and the Public Hospitals Act has a whole bunch of other barriers in it.... It's archaic is what it is.

Although we have a very broad scope of practice in BC, there are a couple of regulations that do create some barriers. So there's some regulations related to some of the different forms that they [NPs] can be responsible for. I'm thinking of things like motor vehicle forms and WCB [Worker's Compensation Board] forms. The NPs aren't able to complete those independently, and they have to have a physician co-signing those. That created a barrier because basically they've [NP] done all the work with the patient but then they have to just involve a physician simply because of the regulation. I know those have been put forward, and there's work underway to have them resolved.

Other examples of barriers included legislation that governs other disciplines and multiple health system activities (CNPI 2006c). For example, when PHCNPs were introduced in Nova Scotia, changes had to be made to the Pharmacy Act so that pharmacists could fill prescriptions written by PHCNPs (Martin-Misener et al. 2004).

Our scoping review identified a need for a pan-Canadian approach to legislative and regulatory framework development and implementation to ensure consistency for PHCNPs (CNPI 2006b, 2006c; Thille and Rowan 2008). This recommendation was supported by the multidisciplinary roundtable convened by CHSRF to formulate evidence-informed policy and practice recommendations based on the synthesis findings (DiCenso et al. 2010c). The CHSRF roundtable specifically recommended that a pan-Canadian approach to regulatory standards and 
requirements would facilitate provider mobility in response to population healthcare needs and improve recruitment and retention to advanced practice nursing roles (DiCenso et al. 2010c).

\section{Inconsistencies in the Educational Preparation of PHCNPs across Canada} Although the CNA (2008), CNPI (2006b) and International Council of Nurses (2008) have specified that graduate degree preparation is required for all advanced practice nursing roles, uptake of this standard for PHCNP education is variable across Canada (Martin-Misener et al. 2010). The need for graduate education for ACNPs and CNSs, both of which typically provide services in organizations with many resources and supports, unlike the PHCNP role, has not been questioned. Only the PHCNP role has been at the centre of the debate over education requirements in Canada (CNPI 2006c; Schreiber et al. 2005). Even if nursing registration and education organizations in provinces and territories decide they want graduate education to be the standard of PHCNP education, their governments may decide the proposed change to the educational requirements for PHCNPs should first be reviewed by the Health Canada and Federal, Provincial, Territorial Advisory Committee on Health Delivery and Human Resources (Dault et al. 2004; Health Canada, and Federal, Provincial, Territorial Advisory Committee on Health Delivery and Human Resources 2006).

The controversy about PHCNP education requirements was reflected in comments from our interview participants. Most participants strongly supported graduate education for all advanced practice nursing roles and told us that until recently the inconsistent educational requirements across provinces had created barriers to the internal mobility of PHCNPs without graduate degrees. One participant used the term "ghettoized" to describe what was happening to PHCNPs educated with a post-baccalaureate or post-diploma certificate, as these PHCNPs could not practise in a province that required graduate education for PHCNPs. This may change now that the Agreement on Internal Trade (AIT) prohibits refusal of a license to a PHCNP, or other professional, previously licensed in another province or territory on the basis of their education qualification (Forum of Labour Market Ministers and Labour Mobility Coordinating Group 2009). Requests for exceptions to the requirements of the Act must justify why a particular measure is needed to meet a "legitimate objective." It remains to be seen what impact the AIT will have on PHCNP mobility and whether provincial nursing organizations will try to defend the need for graduate education for the PHCNP role.

Nursing regulator participants indicated that the requirement for graduate education in British Columbia and Quebec was heavily influenced by physicians, who insisted graduate education should be the basis for the advanced knowledge and skills required of the PHCNP role. Physician endorsement of the need for 
graduate education was regarded as a key facilitator in these provinces. However, a small number of government participants in our synthesis expressed worries about the time lag associated with higher educational standards, the absence of evidence to justify the need for a master's degree, the tuition costs associated with a higher level of training, the impact on the number of NPs in the system and the possibility that NPs would then request higher salaries without increasing patient volume and access.

\section{The Working Relationships between PHCNPs and Family Physicians}

Several papers identified the importance of the working relationship between PHCNPs and family physicians (e.g., Way et al. 2000). Simply stated, if their relationship was good, it was a key facilitator of PHCNP role implementation and integration, but if not good, it became a significant barrier (DiCenso et al. 2003; Nova Scotia Department of Health 2004).

Physician interview participants indicated that positive, respectful and trusting NPphysician relationships, along with good communication, willingness to deal with conflict, organizational structure and matching of personalities, all contributed to NP role integration. One physician we interviewed commented that "if everybody feels they're getting more out of it than they're losing, then it's going to be successful," adding that by working together, NPs and physicians could see more patients, provide better services and ensure patients did not "fall through the cracks."

Nevertheless a large number of papers described physician resistance to the PHCNP role (e.g., Cusson 2004; D’Amour et al. 2009; DiCenso et al. 2003; Hass 2006; Ontario Medical Association and Registered Nurses' Association of Ontario 2003; Pong and Russell 2003; Sloan et al. 2006). The principal reasons for this resistance related to liability concerns (e.g., Bailey et al. 2006; Martin-Misener et al. 2004; Way et al. 2001), scope of practice issues (Beaulieu et al. 2009; DiCenso et al. 2003), lack of role clarity (Beaulieu et al. 2009; D'Amour et al. 2009) and concern about NP independent practice (Gosselin 2001; Laguë 2008). Several reasons for the inter-professional tension between PHCNPs and family physicians were suggested, with some authors attributing it to system factors, such as how the Medicare system structure and funding had established physicians as the gatekeeper to the healthcare system (van der Horst 1992).

Another important reason cited for physician resistance related to the various funding arrangements for physician services. Funding arrangements that created financial competition and an employer-employee relationship between a physician and PHCNP were reported to obstruct collaboration (Jones and Way 2004; Nurse Practitioners' Association of Ontario 2008). The need for adequate compensation models for physicians was stressed by healthcare administrator 
and physician interview participants. Not being able to bill for collaborating with PHCNPs was reported to be a disincentive for physicians to work with them. The literature (Advisory Committee on Health Human Resources et al. 2001; deWitt and Ploeg 2005; DiCenso et al. 2003; Jones and Way 2004; Schreiber et al. 2005) and many interview participants indicated fee-for-service reimbursement impeded PHCNP integration when healthcare activities shifted to NPs and resulted in loss of physician income. One participant explained,

If the physician thinks, if I don't see that person I don't get paid, it's a huge barrier because they don't want somebody else to see that person. Or they want that person [NP] to see them but then they need to see them just so they can get paid. That's a problem to the whole health system.

Participants also highlighted that physicians paid through fee-for-service essentially run their practice as a small business. As such, they have expenses and obligations that other healthcare professionals may not be aware of, as well as a sense of ownership based on their investment in the practice. As one physician explained,

It is often forgotten that the physicians, in our case, own the practice. We've invested in it, we have debts and we bought all the equipment and somehow that doesn't seem to be [recognized].... it is still our business.

Several interview participants commented on how financial incentives for physicians interfered with PHCNP role integration. For example, incentives offered to physicians to hire PHCNPs position the PHCNPs as employees rather than colleagues. The unintended consequences of incentives to physicians for meeting preventive care target numbers were also problematic, because the work of PHCNPs was included in target achievement, yet sharing the incentive was at the discretion of the physician. Voicing their disapproval, the Nurse Practitioners' Association of Ontario stated that "in the spirit of team development, the notion that one provider is being paid an incentive for the work of others is incompatible and inconsistent with the interprofessional approach to care" (2008: 2); instead, they advocated for team-related bonuses. Some primary care practices have converted these physician-specific incentives into team-based incentives in recognition of team members' contributions to preventive care services. A government interview participant commented that remuneration mechanisms need refinement to ensure fair compensation of primary healthcare teams and suggested a team-based approach to remuneration negotiations.

A new practice model for PHCNPs in Ontario is the NP-led clinic, which has had unplanned consequences for relationships between PHCNPs and family physicians. This model was developed to facilitate PHCNPs working collaboratively 
with physicians to provide healthcare to patients who previously did not have a primary healthcare provider (DiCenso et al. 2010a). However, the NP-led clinics encountered strong opposition from the Ontario Medical Association, which alleges that these clinics promote an independent practice model that conflicts with the principles and philosophy of collaborative practice (Ontario Medical Association 2008; DiCenso et al. 2010a); yet these PHCNPs have established strong collaborative relations with the consulting physicians and other healthcare providers who work in these clinics.

There is a recognized overlap in the scope of practice of PHCNPs and family physicians (Marchildon 2005), illustrated clearly by this PHCNP interview participant, who said, "my role really entails a lot of what a family doctor would do." Depending on how well this overlap is understood and managed, it can be a source of tension (Jones and Way 2004; Way et al. 2000). Many interview participants acknowledged the overlap in practice between a PHCNP and family physician, identifying that strong collaborative relationships were needed to negotiate shared areas of practice. One family physician commented,

I think the first step is you sit down and start from square one and say, who are we and what do we really need in this particular setting in terms of a skill set. What is it that you feel comfortable doing? What is it that I'm doing? How can we complement each other? Working through it, sort of compromising.

Another family physician offered further thoughts about the specific approaches PHCNPs and family physicians can use to establish and enhance their collaboration:

So you do it in a very conscientious and concerned fashion to ensure that at the end of the day we're meeting the needs of our patients. We have to make sure that the providers, in this case the NPs and family docs, have worked through how we are going to do this and how do we make sure that we support each other in doing it. So it's a balance between (1) identifying how we can do this, (2) setting up the structures [and] (3) making sure that the other people in the clinic, particularly reception staff, understand their [PHCNP] roles and how to refer to them, because often we leave them [reception and other staff] out and they have no clue.... So that the whole team understands how these roles, how this new team, new way of doing business, is going to unfold, you have to factor in meetings to be able to debrief and figure it out, and you've got to be able to, when it's not working, talk about it. You have to look at the professional development that's needed for individuals both in terms of their clinical skills as well as potentially just to understand how you work as a team. 
Many of these suggestions were also found in the literature. For example, some authors advocated for a structured approach to developing collaboration that emphasizes the importance of respect, communication and trust (Jones and Way 2004; Way et al. 2000, 2001). Others reported specific strategies to improve communication and collaboration, such as collaborative practice agreements that plainly define mutual responsibilities (Martin-Misener et al. 2004; Sebas 1994), clearly established prompt communication mechanisms (Donald et al. 2009) and processes to recognize and openly explore "turf protection" in the context of the public's need for accessible quality healthcare (Caprio 2006; Donald et al. 2009).

\section{Discussion}

The purpose of this paper was to provide an overview of the current status of the PHCNP role in Canada and the challenges impeding full integration of the role into the Canadian healthcare system based on the findings from our decision support synthesis. The numbers of PHCNPs are increasing in Canada, they are practising in a wide range of practice settings and PHCNPs are supported with legislation and regulation in every province and territory. It remains to be seen whether this trend will continue nationally and whether the increase in the uptake of the PHCNP role will be evident in all provinces and territories. Ongoing studies are needed to monitor these trends. While several provinces are gathering annual data about PHCNPs in their own jurisdictions, a national tracking method is needed to better understand and compare nationwide practice pattern trends and barriers to practice. A national tracking system could facilitate comparisons and contrasts of PHCNP practice in different contexts and settings, thereby informing policy, scope of practice and legislative decisions.

While much has been accomplished to advance the implementation and integration of PHCNPs in Canada, a number of hurdles and obstacles block the path to full integration and sustainability of the role. Our synthesis findings and the recommendations from the CHSRF roundtable point to the need for clear, consistent legislation and education standards across all provinces and territories to support PHCNP role clarity, credibility and portability.

The restrictions on PHCNPs' legislated scope of practice interfere with the ultimate goal of providing safe, effective and timely care for patients. Limiting the ability of PHCNPs to prescribe and adjust patients' medications based on the most recent evidence and the inability to refer patients directly to a specialist result in additional system costs and delays for patients, 
because they must first see a family physician. Moreover, the drugs and diagnostic tests that a PHCNP orders in a community health centre, a traditional setting in which PHCNPs practice and for which drug lists usually have been designed, may be quite different from the typical tests and medications required in a nursing home, emergency department or palliative care setting, some of the newer settings in which PHCNPs are practising. In addition to prescribing policies, each province and territory will need to review the various legal acts and regulations that form the basis of health and social policy to identify and remove barriers to NP practice in order to improve the quality and efficiency of primary healthcare. The same process needs to occur at the federal level. The extent of the legislation and policy changes needed is astonishing; see for example, the legislated restrictions on NP practice identified in the frequently asked questions in the newly released NP toolkit developed by the College of Registered Nurses of Nova Scotia (2010).

A number of Canadian jurisdictions have a health professions act that provides a regulatory structure to govern registered nurses, physicians, NPs and other regulated healthcare professionals (College of Registered Nurses of British Columbia 2010). Provincial and territorial acts, policy and dialogue among and between professions typically help to determine the specific bylaws and regulations that determine scope of practice in each province and territory. The emphasis on primary healthcare has enhanced the shared scope of practice between PHCNPs and family physicians. These shared areas of practice are highly valued because they facilitate timely patient access to primary healthcare services. However, tensions between PHCNPs and physicians can arise when there are misunderstandings of the differences between autonomous and independent practice and when funding requirements impede collaboration and delay the provision of healthcare services. The context of contemporary healthcare reform is requiring many healthcare professions to adjust to changes in the activities they and others carry out, creating fears related to loss of autonomy and control and leading to resistance. Healthcare team collaboration depends on respect, trust, and mutual understanding of and willingness to negotiate and re-negotiate professional roles. It depends on a non-hierarchical dynamic and a conviction that every healthcare team member is "getting more out of it than they are losing."

The variability in educational preparation may place PHCNPs with graduate degrees at an advantage when applying for jobs, compared with their post-baccalaureate-prepared colleagues. A graduate degree typically prepares PHCNPs to practise at an advanced level (i.e., critiquing research and its 
application to patient care, purposely selecting and applying theories based on patient needs, leading community development and healthcare intervention programs, and evaluating and understanding policy and ways to influence it). The roundtable recommended that in order to facilitate provider mobility in response to population healthcare needs and improve recruitment and retention to advanced practice nursing roles, a pan-Canadian approach should be taken, in collaboration with educators, to standardize advanced practice nursing educational standards, requirements and processes (DiCenso et al. 2010c). The inclusion of policy makers in these discussions is critical in order for educators and policy makers to understand and appreciate their mutual concerns regarding health human resources and quality of healthcare. Following agreement on educational standards, an accreditation or another type of review process for PHCNP education programs is important to ensure that educational institutions adhere to the national standards.

The interest in the PHCNP role is closely tied to the reawakened nationwide awareness of the importance of primary healthcare in renewing and sustaining the publicly funded healthcare system that Canadians clearly value (Romanow 2002). Increasingly, evidence and value for money are becoming key considerations in decision making about the initiation and continuation of innovations (Health Council of Canada 2009). The need for further research to better understand the benefits of the care provided by PHCNPs was underscored by the CHSRF roundtable (DiCenso et al. 2010c). Some of this evidence is beginning to accumulate in Canada. Russell et al. (2009) found that the inclusion of PHCNPs in primary healthcare models in Ontario was associated with improved chronic disease management and that longer patient consultations benefited those with chronic conditions. Other studies have shown that healthcare teams that include PHCNPs improve accessibility to primary healthcare, especially in rural areas (Centre for Rural and Northern Health Research 2006; Martin-Misener et al. 2009). In addition, an Ontario study found that the addition of PHCNPs to an emergency department resulted in a significant reduction in wait times, length of stay and left-without-treatment rates (Ducharme et al. 2009). A similar study in Alberta found reduced wait times and improved throughput for low-acuity patients (Steiner et al. 2009). Patient satisfaction with the role continues to be high; according to a July 2009 Harris/Decima survey, the Canadian public is increasingly aware of and comfortable with NPs, and many more citizens are willing to see an NP instead of their physician than have had the opportunity to do so (Harris/Decima 2009). 


\section{Conclusion}

In summary, there is a need for a pan-Canadian approach to the education, supply, legislation and regulation of PHCNPs that builds on the foundational work of the CNPI. The overlapping scope of practice between PHCNPs and family physicians requires open dialogue and recognition of the historical context of role development to enable both professions to work collaboratively to provide optimal care to patients in an effective healthcare system for all Canadians.

\section{Acknowledgements}

The synthesis from which this work was derived was made possible through joint funding by the Canadian Health Services Research Foundation and the Office of Nursing Policy of Health Canada. We thank the librarians who conducted searches of the electronic databases, Tom Flemming at McMaster University and Angella Lambrou at McGill University. Chris Cotoi and Rick Parrish in the Health Information Research Unit (HIRU) at McMaster University created the electronic literature extraction tool for the project. We thank all those who took time from their busy schedules to participate in key informant interviews and focus groups. The following staff members provided excellent support: Heather Baxter, Renee Charbonneau-Smith, R. James McKinlay, Dianna Pasic, Julie Vohra, Rose Vonau, and Brandi Wasyluk. Special thanks go to our advisory board, roundtable participants and Dr. Brian Hutchison for their thoughtful feedback and suggestions.

\section{References}

Advisory Committee on Health Human Resources and The Centre for Nursing Studies in collaboration with The Institute for the Advancement of Public Policy, Inc. 2001. Final Report: The Nature of the Extended/Expanded Nursing Role in Canada. St. John's, NL: Centre for Nursing Studies. Retrieved September 12, 2009.<http://www.cns.nf.ca/research/finalreport.htm>.

Bailey, P., L. Jones and D. Way. 2006. “Family Physician/Nurse Practitioner: Stories of Collaboration.” Journal of Advanced Nursing 53(4): 381-91.

Beaulieu, M.D., L. Samson, G. Rocher, M. Rious, L. Boucher and C. Del Grande. 2009. “Investigating the Barriers to Teaching Family Physicians' and Specialists' Collaboration in the Training Environment: A Qualitative Study." BMC Medical Education 9(31). Retrieved September 7, 2009. $<$ http://www.biomedcentral.com/content/pdf/1472-6920-9-31.pdf $>$.

Bryant-Lukosius, D. and A. DiCenso. 2004. "A Framework for the Introduction and Evaluation of Advanced Practice Nursing Roles." Journal of Advanced Nursing 48(5): 530-40.

Bryant-Lukosius, D., A. DiCenso, G. Browne and J. Pinelli. 2004. “Advanced Practice Nursing Roles: Development, Implementation, and Evaluation." Journal of Advanced Nursing 48(5): 519-29.

Canadian Institute for Health Information. 2010. Regulated Nurses: Canadian Trends, 2004-2008. Updated February 2010. Ottawa, ON: CIHI. Retrieved March 21, 2010. <http://secure.cihi.ca/ cihiweb/products/regulated_nurses_2004_2008_en.pdf $>$.

Canadian Institute for Health Information and Canadian Nurses Association. 2006. The Regulation and Supply of Nurse Practitioners in Canada: 2006 Update. Ottawa, ON: CIHI. Retrieved August 
30, 2009.<http://secure.cihi.ca/cihiweb/products/The_Nurse_Practitioner_Workforce_in_ Canada_2006_Update_final.pdf>.

Canadian Medical Protective Association and Canadian Nurse Protective Society. 2005. CMPA / CNPS Joint Statement on Liability Protection for Nurse Practitioners and Physicians in Collaborative Practice. Ottawa, ON: Canadian Nurse Protective Society. Retrieved September 7, 2009.<http://www. cnps.ca/joint_statement/joint_statement_e.html>.

Canadian Nurse Practitioner Initiative. 2006a. Implementation and Evaluation Toolkit for Nurse Practitioners in Canada. Ottawa, ON: CNPI. Retrieved September 12, 2009. <http://www.cna-aiic.ca/ CNA/documents/pdf/publications/Toolkit_Implementation_Evaluation_NP_e.pdf $>$.

Canadian Nurse Practitioner Initiative. 2006b. Nurse Practitioners: The Time Is Now. A Solution to Improving Access and Reducing Wait Times in Canada. Ottawa, ON: CNPI. Retrieved August 12, 2009. $<$ http://206.191.29.104/documents/pdf/Nurse_Practitioners_The_Time_is_Now_e.pdf $>$.

Canadian Nurse Practitioner Initiative. 2006c. Nurse Practitioners: The Time Is Now Technical Reports. Ottawa, ON: CNPI. Retrieved August12, 2009.<http://www.cna-aiic.ca/CNA/practice/ advanced/initiative/evaluation/default_e.aspx $>$.

Canadian Nurses Association. 2003. Joint Position Statement. Scopes of Practice. Ottawa, ON: CNA. Retrieved September 7, 2009. <http://www.cna-nurses.ca/CNA/documents/pdf/publications/PS66_ Scopes_of_practice_June_2003_e.pdf $>$.

Canadian Nurses Association. 2005. Canadian Nurse Practitioner Core Competency Framework. Ottawa, ON: CNA. Retrieved March 2, 2009. <http://www.rnantnu.ca/Portals/0/Documents/ Registration\%202007/NP\%20Application/CNPE_Core_Competency_Framework_e.pdf > .

Canadian Nurses Association. 2008. Advanced Nursing Practice: A National Framework. Ottawa, ON: CNA. Retrieved September 20, 2010. <http://www.cna-aiic.ca/CNA/documents/pdf/publications/ ANP_National_Framework_e.pdf $>$.

Canadian Nurses Association. 2009. Position Statement: The Nurse Practitioner. Ottawa, ON: CNA. Retrieved April 5, 2010. <http://www.cna-aiic.ca/CNA/documents/pdf/publications/PS_Nurse_ Practitioner_e.pdf $>$.

Canadian Nurses Association. 2010. Canadian Nurse Practitioner Core Competency Framework. Ottawa, ON: CNA. Retrieved September 20, 2010. <http://www.cna-aiic.ca/CNA/documents/pdf/ publications/Competency_Framework_2010_e.pdf>.

Caprio, T.V. 2006. "Physician Practice in the Nursing Home: Collaboration with Nurse Practitioners and Physician Assistants." Annals of Long Term Care 14(3):17-24.

Carter, N., R. Martin-Misener, K. Kilpatrick, S. Kaasalainen, F. Donald, D. Bryant-Lukosius, P. Harbman, I. Bourgeault and A. DiCenso. 2010. "The Role of Nursing Leadership in Integrating Clinical Nurse Specialists and Nurse Practitioners in Healthcare Delivery in Canada." Canadian Journal of Nursing Leadership 23(Special Issue December): 167-85.

Caty, S., I. Michel, R. Pong and D. Stewart. 2000. "Nurse Practitioner Graduates: Where Are They Now?" Registered Nurse Journal 12(2): 6-8.

Centre for Rural and Northern Health Research. 2006. Primary Health Care Nurse Practitioners: Who Are They? What Do They Do? Sudbury, ON: Centre for Rural and Northern Health Research, Laurentian University. Retrieved March 18, 2010. <http://www.cranhr.ca/pdf/focus/FOCUS06-A3.pdf>.

Chambers, L.W. and A.E. West. 1978. “The St John's Randomized Trial of the Family Practice Nurse: Health Outcomes of Patients.” International Journal of Epidemiology 7(2): 153-61.

College of Registered Nurses of British Columbia. 2009. Fact Sheet: Nurse Practitioner Examinations. Vancouver, BC: College of Registered Nurses of British Columbia. Retrieved March 18, 2010. $<$ https://www.crnbc.ca/Registration/NursePractitionerRen/Documents/423_FS_NP_Exam_ Dec09.pdf $>$.

College of Registered Nurses of British Columbia. 2010. Overview of Health Professions Act, Nurses (Registered) and Nurse Practitioners Regulation, CRNBC Bylaws. Vancouver, BC: College of Registered Nurses of British Columbia. Retrieved March 21, 2010. <https://www.crnbc.ca/downloads/324.pdf $>$. 
College of Registered Nurses of Nova Scotia. 2010. NP Toolkit. Halifax, NS: College of Registered Nurses of Nova Scotia. Retrieved December 15, 2010. <http://www.crnns.ca/default. asp? $\mathrm{mn}=414.1116 .1457 .2642>$.

Cragg, C.E., S. Doucette and J. Humbert. 2003. “Ten Universities, One Program: Successful Collaboration to Educate Nurse Practitioners." Nurse Educator 28(5): 227-31.

Cusson, L. 2004. “Loi 90: Quels en Seront les Impacts?" L'OMNI : Bulletin De l'Association Des Médecins Omnipraticiens du Québec 27(1): 4-6.

D’Amour, D., D. Tremblay and M. Proulx. 2009. 'Déploiement de Nouveaux Rôles Infirmiers au Québec et Pouvoir Médical." Recherches Sociographiques 50(2): 301-20.

Dault, M., J. Lomas and M. Barer on behalf of the Listening for Directions II Partners. 2004.

Listening for Direction II: National Consultation on Health Services and Policy Issues for 2004-2007.

Ottawa, ON: Canadian Health Services Research Foundation. Retrieved December 28, 2010. <http:// www.cihr-irsc.gc.ca/e/24509.html>.

de Witt, L. and J. Ploeg. 2005. "Critical Analysis of the Evolution of a Canadian Nurse Practitioner Role." Canadian Journal of Nursing Research 37(4): 116-37.

DiCenso, A., L. Auffrey, D. Bryant-Lukosius, F. Donald, R. Martin-Misener, S. Matthews and J. Opsteen. 2007. "Primary Health Care Nurse Practitioners in Canada." Contemporary Nurse 26(1): $104-15$.

DiCenso, A., I. Bourgeault, J. Abelson, R. Martin-Misener, S. Kaasalainen, N. Carter, P. Harbman, F. Donald, D. Bryant-Lukosius and K. Kilpatrick. 2010a. "Utilization of Nurse Practitioners to Increase Patient Access to Primary Healthcare in Canada - Thinking Outside the Box." Canadian Journal of Nursing Leadership 23(Special Issue December): 239-59.

DiCenso, A., D. Bryant-Lukosius, I. Bourgeault, R. Martin-Misener, F. Donald, J. Abelson, S. Kaasalainen, K. Kilpatrick, S. Kioke, N. Carter and P. Harbman. 2010b. Clinical Nurse Specialists and Nurse Practitioners in Canada: A Decision Support Synthesis. Retrieved December 28, 2010. <http:// www.chsrf.ca/SearchResultsNews/10-06-01/b9cb9576-6140-4954-aa57-2b81c1350936.aspx>.

DiCenso, A., R. Martin-Misener, D. Bryant-Lukosius, I. Bourgeault, K. Kilpatrick, F. Donald, S. Kaasalainen, P. Harbman, N. Carter, S. Kioke, J. Abelson, R.J. McKinlay, D. Pasic, B. Wasyluk, J. Vohra and R. Charbonneau-Smith. 2010c. "Advanced Practice Nursing in Canada: Overview of a Decision Support Synthesis." Canadian Journal of Nursing Leadership 23(Special Issue December): 15-34.

DiCenso, A., G. Paech and IBM Corporation. 2003. Report on the Integration of Primary Health Care Nurse Practitioners into the Province of Ontario. Toronto, ON: Ministry of Health and Long-Term Care. Retrieved August 12, 2009. <http://www.health.gov.on.ca/english/public/pub/ministry_ reports/nurseprac03/nurseprac03_mn.html $>$.

Dierick-van Daele, A., L. Steuten, J. Metsemakers, E. Derckx, C. Spreeuwenberg and H. Vrijhoef. 2010. "Economic Evaluation of Nurse Practitioners Versus GPs in Treating Common Conditions." British Journal of General Practice 60(570): e28-35.

Donald, F., E.A. Mohide, A. DiCenso, K. Brazil, M. Stephenson and N. Akhtar-Danesh. 2009. "Nurse Practitioner and Physician Collaboration in Long-Term Care Homes: Survey Results." Canadian Journal on Aging 28(1): 77-87.

Ducharme, J., R. Alder, C. Pelletier, D. Murray and J. Tepper. 2009. “The Impact on Patient Flow after the Integration of Nurse Practitioners and Physician Assistants in 6 Ontario Emergency Departments." Canadian Journal of Emergency Medical Care 11(5): 455-61.

Fahey-Walsh, J. 2004. Practice Component: Literature Review Report. Advanced Nursing Practice and the Primary Health Care Nurse Practitioner: Title, Scope and Role. Ottawa, ON: The Canadian Nurse Practitioner Initiative and the Canadian Nurses Association. Retrieved December 15, 2010. <http:// www.cna-nurses.ca/CNA/documents/pdf/publications/cnpi/tech-report/section3/06_PracticeFW_ AppendixB.pdf $>$.

Forum of Labour Market Ministers and Labour Mobility Coordinating Group. 2009. Guidelines for Meeting the Obligations of the Labour Mobility Chapter. Ottawa, ON: Forum of Labour Market Ministers. Retrieved November 15, 2010. < http://www.ait-aci.ca/labour_en/Labour\%20 
Mobility\%20Guidelines\%20June\%2025\%202009\%20Final.pdf >.

Goss Gilroy Inc. Management Consultants. 2001. Report on the Evaluation of Implementation of the Role of Nurse Practitioner-Primary Health Care in Newfoundland and Labrador. St. John's, NL: Health and Community Services Province of Newfoundland and Labrador.

Gosselin, S. 2001. Les infirmières praticiennes à l'urgence. Prise de position de l'association des médecins d’urgence du Québec. Québec-Ville, QC: L'Association des Médecins d’Urgence du Québec. Retrieved December 28, 2010. < http://www.amuq.qc.ca/assets/memoires-et-positions/Les_Infirmieres_ praticiennes_a_l_urgence_3.pdf?phpMyAdmin=i\%2CheTT\%2CBhLKb96mm75DwfLeUjab >.

Gould, O.N., D. Johnstone and L. Wasylkiw. 2007. "Nurse Practitioners in Canada: Beginnings, Benefits, and Barriers." Journal of the American Academy of Nurse Practitioners 19(4): 165-71.

Gouvernement du Québec. 2005. "Règlement sur les classes de pécialités de l'Ordre des Infirmières et Infirmiers de Québec pour l'exercice des activités visées par l'article 36.1 de la loi sur les Infirmières et Infirmiers." Gazette Officielle du Québec 45: 6367-84.

Government of Yukon. 2009. Act to Amend the Registered Nurses Profession Act. Whitehorse, YT: Government of Yukon. Retrieved March 18, 2010. <http://www.gov.yk.ca/legislation/acts/ata_ renupr.pdf $>$.

Graydon, J. and J. Hendry. 1977. "Outpost Nursing in Northern Newfoundland.” Canadian Nurse 73(8): 34-7.

Harris/Decima. 2009, August 13. Canadians Very Comfortable with Expanded Role for Nurse Practitioners. [Press release] Ottawa, ON: Harris/Decima. Retrieved March 21, 2010. <http://sdnpc. ca/images/stories/canadians_very_comfortable_with_expanded_role_for_nurse_practitioners.doc $>$.

Hass, J. 2006. "Nurse Practitioners Now Able to Work across Canada." Canadian Medical Association Journal 174(7): 911-2.

Health Canada, \& Federal, Provincial, Territorial Advisory Committee on Health Delivery and Human Resources. 2006. Pan-Canadian HHR Planning Framework Consultation Workshop. Ottawa, ON: Federal, Provincial, Territorial Advisory Committee on Health Delivery and Human Resources. Toronto, ON: Practical Nurses Canada. Retrieved March 28, 2010. <http://www.pncanada.ca/hhr_ meeting_summary.doc $>$.

Health Council of Canada. 2009. Value for Money: Making Canadian Health Care Stronger. Ottawa, ON: Health Council of Canada. Retrieved March 26, 2010. <http://www2.infoway-inforoute.ca/ Documents/HCC_VFMReport_WEB.pdf>.

Horrocks, S., E. Anderson and C. Salisbury. 2002. "Systematic Review of Whether Nurse Practitioners Working in Primary Care Can Provide Equivalent Care to Doctors." British Medical Journal 324(7341): 819-23.

Humbert, J., F. Legault, S. Dahrouge, B. Halabisky, G. Boyce, W. Hogg and S. Amos. 2007. "Integration of Nurse Practitioners into a Family Health Network." Canadian Nurse 103(9): 30-4.

Hutchison, B. 2008. "A Long Time Coming: Primary Healthcare Renewal in Canada." Healthcare Papers 8(2): 10-24. Retrieved March 21, 2010. <http://www.longwoods.com/content/19704>.

International Council of Nurses. 2008. The Scope of Practice, Standards and Competencies of the Advanced Practice Nurse. Geneva: International Council of Nurses.

Jones, L. and D. Way. 2004. Practice Component: Literature Review Report. Delivering Primary Health Care to Canadians: Nurse Practitioners and Physicians in Collaboration. Ottawa, ON: Canadian Nurses Association and Canadian Nurse Practitioner Initiative. Retrieved December 15, 2010. <http://web.archive.org/web/20060807182745/www.cnpi.ca/documents/pdf/Models_of_ Collaboration_Literature_Review_e.pdf $>$.

Kaasalainen, S., R. Martin-Misener, K. Kilpatrick, P. Harbman, D. Bryant-Lukosius, F. Donald, N. Carter and A. DiCenso. 2010. "A Historical Overview of the Development of Advanced Practice Nursing Roles in Canada." Canadian Journal of Nursing Leadership 23(Special Issue December): 35-60.

Kergin, D.J., M.A. Yoshida, W.O. Spitzer, J.E. Davis and E.M. Buzzell. 1973. "Changing Nursing Practice through Education." Canadian Nurse 69(4): 28-31. 
Kirby, M. 2002. The Health of Canadians - The Federal Role. Final Report. Ottawa, ON: Parliament of Canada. Retrieved July 10, 2009. <http://www.parl.gc.ca/37/2/parlbus/commbus/senate/com-e/ SOCI-E/rep-e/repoct02vol6-e.htm>.

Kulig, J., E. Thomlinson, F. Curran, D. Nahachewsky, M. Macleod, N. Stewart and R. Pitblado. 2003. Rural and Remote Nursing Practice: An Analysis of Policy Documents. Prince George, BC: University of Northern British Columbia. Retrieved September 2, 2009. <http://ruralnursing.unbc.ca/reports/ jkulig/FinalReportweb.pdf $>$.

Laguë, G. 2008. “Do Nurse Practitioners Pose a Threat to Family Physicians? Yes.” Canadian Family Physician 54: 1668, 1670.

Marchildon, G.P. 2005. "Health Systems in Transition: Canada." European Observatory on Health Systems and Policies 7(3): 1-156. Retrieved September 2, 2009. <http://www.euro.who.int/document/ e87954.pdf>.

Martin-Misener, R., D. Bryant-Lukosius, P. Harbman, F. Donald, S. Kaasalainen, N. Carter, K. Kilpatrick and A. DiCenso. 2010. "Education of Advanced Practice Nurses in Canada." Canadian Journal of Nursing Leadership 23(Special Issue December): 61-84.

Martin-Misener, R., B. Downe-Wamboldt, E. Cain and M. Girouard. 2009. "Cost Effectiveness and Outcomes of a Nurse Practitioner-Paramedic-Family Physician Model of Care: The Long and Brier Islands Study." Primary Health Care Research \& Development 10(1): 14.

Martin-Misener, R., J. McNab, I.S. Sketris and L. Edwards. 2004. "Collaborative Practice in Health Systems Change: The Nova Scotia Experience with the Strengthening Primary Care Initiative." Canadian Journal of Nursing Leadership 17(2): 33-45. Retrieved September 2, 2009. <http://www. longwoods.com/conent/16345>.

Mhatre, S.L. and R.B. Deber. 1992. "From Equal Access to Health Care to Equitable Access to Health: A Review of Canadian Provincial Health Commissions and Reports." International Journal of Health Services 22(4): 645-68.

Ministry of Health and Long-Term Care. 2009. Bill 179. An Act to Amend Various Acts Related to Regulated Health Professions and Certain Other Acts. Retrieved March 23, 2010. <http://www.ontla. on.ca/bills/bills-files/39_Parliament/Session1/b179ra.pdf >.

Nova Scotia Department of Health. 2004. Strengthening Primary Care in Nova Scotia: Summary of the Evaluation Results. Halifax, NS: Nova Scotia Department of Health.

Nurse Practitioners' Association of Ontario. 2007. Critical Legislative and Regulatory Steps to Improve Access to Care for Patients and Facilitate Integration of Nurse Practitioners in Ontario. Toronto, ON: Nurse Practitioners' Association of Ontario. Retrieved September 12, 2009. $<$ http://www.npao.org/Uploads/members/HPRAC\%20Submission\%20Referral\%20Extended\%20 Class\%20Nurse\%20final.pdf>.

Nurse Practitioners' Association of Ontario. 2008. Position Statement: Team-Related Bonuses is the Correct Way to Go. Toronto, ON: Nurse Practitioners' Association of Ontario. Retrieved September 12, 2009. <http://www.npao.org/Uploads/members/Position\%20Statement\%20Team\%20Based $\% 20$ Bonuses\%20Correct\%20Way\%20to\%20Go\%20Mar\%20.pdf > .

Nurse Practitioners' Association of Ontario. 2009. Submission to: Hon. David Caplan. Response to the HPRAC Referral "A Report to the Minister of Health and Long-Term Care on the Review of the Scope of Practice of Registered Nurses in the Extended Class (Nurse Practitioners) March 2008." Toronto, ON: Nurse Practitioners' Association of Ontario. Retrieved March 21, 2010. <http://www. npao.org/Uploads/members/NPAO\%20Submission\%20to\%20Minister\%20Caplan\%20on\%20 HPRAC\%20Referral\%20on\%20RN(EC)s\%202008.pdf>.

Ontario Medical Association. 2008. Ontario Medical Association Raises Concerns Over Expansion of Nurse Practitioner Clinics. Toronto, ON: Ontario Medical Association. Retrieved November 15, 2010. $<$ https://www.oma.org/Mediaroom/PressReleases/Pages/Ontario'sDoctorsDiscouragedbyProvincial HealthCareSpending.aspx $>$.

Ontario Medical Association and Registered Nurses' Association of Ontario. 2003. The RN(EC)-GP Relationship: A Good Beginning. Toronto, ON: Registered Nurses' Association of Ontario. Retrieved November 15, 2010. < http://www.rnao.org/Storage/12/712_RNAO_OMA_Report.pdf >. 
Ordre des infirmières et infirmiers du Québec. 2009. Les infirmières praticiennes spécialisées: un rôle à propulser, une intégration à accélérer. Bilan et perspectives de pérennité. Montreal, QC: Ordre des infirmières et infirmiers du Québec. Retrieved August 14, 2009. <http://www.oiiq.org/uploads/ publications/memoires/IPS_Memoire.pdf $>$.

Pong, R.W. and N. Russell. 2003. A Review and Synthesis of Strategies and Policy Recommendations on the Rural Health Workforce. Sudbury, ON: Centre for Rural and Northern Health Research, Laurentian University. Retrieved September 7, 2009. <http://www.martes.laurentian.ca/NR/rdonlyres/93AB730E5D37-4E50-B490-12E80F3433A1/0/TORC_RuralhealthworkforcesynthesisfinaldraftMay.pdf > .

Prendergast, P. 2009. Enhancing Mobility of Nurse Practitioners in Canada. Presented at Conference of Canadian Association of Advanced Practice Nurses. St. John's, NL.

Romanow, R.J. 2002. Building on Values: The Future of Health Care in Canada - Final Report. Ottawa, ON: Commission on the Future of Health Care in Canada. Retrieved March 18, 2010. <http://www. cbc.ca/healthcare/final_report.pdf $>$.

Russell, G.M., S. Dahrouge, W. Hogg, R. Geneau, L. Muldoon and M. Tuna. 2009. "Managing Chronic Disease in Ontario Primary Care: The Impact of Organizational Factors." Annals of Family Medicine 4(4): 309-18.

Schreiber, R., M. MacDonald, B. Pauly, H. Davidson, J. Crickmore, L. Moss, J. Pinelli and S. Regan. 2005. "Singing from the Same Songbook: The Future of Advanced Nursing Practice in British Columbia." Canadian Journal of Nursing Leadership 18(2). Retrieved September 18, 2009. <http:// www.longwoods.com/content/19027>.

Sebas, M.B. 1994. "Developing a Collaborative Practice Agreement for the Primary Care Setting." Nurse Practitioner 19(3): 49-51.

Sidani, S., D. Irvine and A. DiCenso. 2000. "Implementation of the Primary Care Nurse Practitioner Role in Ontario." Canadian Journal of Nursing Leadership 13(3): 13-9. Retrieved September 18, 2009. $<$ http://www.longwoods.com/content/16302>.

Sloan, C., R. Pong, E. Rukholm and S. Caty. 2006. Nurse Practitioner Workforce Survey and NPAO Electronic Registry Project Report. Centre for Rural and Northern Health Research, Laurentian University. Retrieved September 12, 2009. <http://www.cranhr.ca/pdf/NP_Registry_fin2006.pdf >.

Spitzer, W.O. 1984. “The Nurse Practitioner Revisited: Slow Death of a Good Idea.” New England Journal of Medicine 310(16): 1049-51.

Spitzer, W.O., D.J. Kergin, M.A. Yoshida, W.A. Russell, B.C. Hackett and C.H. Goldsmith. 1973. "Nurse Practitioners in Primary Care. III. The Southern Ontario Randomized Trial." Canadian Medical Association Journal 108(8): 1005.

Spitzer, W.O., D.L. Sackett, J.C. Sibley, R.S. Roberts, M. Gent, D.J. Kergin, B.C. Hackett and A. Olynich. 1974. "The Burlington Randomized Trial of the Nurse Practitioner." New England Journal of Medicine 290(5): 251-6.

Steiner, I., D. Nichols, S. Blitz, L. Tapper, A. Stagg, L. Sharma and C. Policicchio. 2009. "Impact of a Nurse Practitioner on Patient Care in a Canadian Emergency Department." Canadian Journal of Emergency Medical Care 11(3), 207-14.

Stoddart, G. and M. Barer. 1992. “Toward Integrated Medical Resource Policies for Canada: 11. Improving Effectiveness and Efficiency." Canadian Medical Association Journal 147(11): 1653-60.

Stolee, P., L.M. Hillier, J. Esbaugh, N. Griffiths and M.J. Borrie. 2006. "Examining the Nurse Practitioner Role in Long-Term Care: Evaluation of a Pilot Project in Canada." Journal of Gerontological Nursing 32(10): 28-36.

Thille, P. and M.S. Rowan. 2008. The Role of Nurse Practitioners in the Delivery of Primary Health Care: A Literature Review. Unpublished report submitted to Health Canada.

Turris, S., S. Knoll, B. Hayhoe, T. Freeman, M. Wilson, F. Forster and M. Homack. 2005. "Nurse Practitioners in British Columbia." Canadian Nurse 101(3): 20-4.

van der Horst, M.L. 1992. "Canada's Health Care System Provides Lessons for NPs." Nurse Practitioner 17(8): 44, 50-3, 57 passim. 
van Soeren, M., C. Hurlock-Chorostecki, S. Goodwin and E. Baker. 2009. “The Primary Healthcare Nurse Practitioner in Ontario: A Workforce Study." Canadian Journal of Nursing Leadership 22(2): 58-72. Retrieved September 12, 2009. <http://www.longwoods.com/content/20798>.

Way, D., L. Jones, B. Baskerville and N. Busing. 2001. "Primary Health Care Services Provided by Nurse Practitioners and Family Physicians in Shared Practice." Canadian Medical Association Journal 165(9): 1210-4.

Way, D., L. Jones and N. Busing. 2000. Implementation Strategies: Collaboration in Primary CareFamily Doctors \& Nurse Practitioners Delivering Shared Care. Retrieved December 28, 2010. $<$ http://www.ocfp.on.ca/English/OCFP/Communications/Publications/default.asp?s=1 >. 